\title{
Mortality in a cohort of Egyptian systemic lupus erythematosus patients: retrospective two-center study
}

\author{
Abdelkawy Moghazy ${ }^{1}$ and Amira M. Ibrahim² ${ }^{2^{*}}$
}

\begin{abstract}
Background: Systemic lupus erythematosus is a debilitating autoimmune disease with major contribution to the worldwide morbidity and mortality. This study aimed to investigate the causes of mortality in systemic lupus erythematosus (SLE) patients and the relation between clinical activity, disease-associated end-organ damage, laboratory markers and mortality.
\end{abstract}

Results: Among the 771 patients who were successfully followed up, 34 patients (4.4\%) died. The leading causes of death were infectious causes (35.29\%), cardiopulmonary causes (26.48\%), renal causes (14.7\%), unknown causes (14.7\%), neuropsychiatric causes (5.88\%), and lastly gastrointestinal causes (2.94\%). Subjects who died had lower complement 3 level, more anemia, lymphopenia, neutropenia, leukocytosis, thrombocytopenia, decreased glomerular filtration rate, higher incidence of infection, end-stage renal disease, and cardiopulmonary complications. Higher glucocorticoid dosage with more immunosuppressant (mofetil and cyclophosphamide) treatment was observed in patients who died. SLE disease Activity Index and Systemic Lupus International Collaborating Clinics damage index were both significantly higher in deceased persons. Multivariable hazards regression analysis revealed that lymphopenia $(p=0.017)$, decreased glomerular filtration rate $<50 \%(p=0.002)$ with end-stage renal disease $(p=0.001)$, and high steroid daily use of $>40 \mathrm{mg}(p=0.016)$ were independent risk factors for the mortality of SLE patients.

Conclusion: Infections and cardiopulmonary complications are the leading causes of death in two centers caring for Egyptian SLE patients. Lymphopenia, end-stage renal failure, and high steroid daily use were associated with poor outcomes.

Keywords: Mortality, Lupus, Infections, Cardiopulmonary, Egyptian

\section{Background}

Systemic lupus erythematosus (SLE) is a multisystem autoimmune disease, occurring most frequently in women during reproductive period of life with a female to male ratio of 10:1. It is a debilitating autoimmune disease with major contribution to the worldwide morbidity and mortality. This chronic, multisystem disease is characterized by widespread affections of different body organs in a progressive pattern with recurrent exacerbating attacks $[1,2]$.

The risk of mortality in patients with SLE has previously been documented to range from twofold to fivefold relative to the general population [3-6]. Men are more likely to have higher mortality rates and a higher rate of fulminant illness than women with SLE [7]. In contrast to earlier controls, survival has improved dramatically $[8,9]$. Mortality rates tend to differ across race,

\footnotetext{
* Correspondence: amiraibrahim1110@gmail.com

${ }^{2}$ Faculty of Medicine, Kafr El Sheikh University, Kafr El Sheikh, Egypt

Full list of author information is available at the end of the article
}

\section{Springer Open}

(- The Author(s). 2021 Open Access This article is licensed under a Creative Commons Attribution 4.0 International License, which permits use, sharing, adaptation, distribution and reproduction in any medium or format, as long as you give appropriate credit to the original author(s) and the source, provide a link to the Creative Commons licence, and indicate if changes were made. The images or other third party material in this article are included in the article's Creative Commons licence, unless indicated otherwise in a credit line to the material. If material is not included in the article's Creative Commons licence and your intended use is not permitted by statutory regulation or exceeds the permitted use, you will need to obtain permission directly from the copyright holder. To view a copy of this licence, visit http://creativecommons.org/licenses/by/4.0/. 
ethnicity, and region, so when looking at the data, it is very important to keep all these factors in mind. Lupus was viewed as a rapidly lethal disease in the early to the mid-20th century, as medical options were limited and deficient. The predicted 5-year survival of SLE patients was almost $50 \%$ during the 1950 s. Diagnostic methods and interventions were not so advanced; thus, it took longer to diagnose and thoroughly treat patients [10]. Studies of Afro-Caribbean women in Barbados [11] have shown a very high incidence of SLE and lupus nephritis (LN), as well as a high mortality rate and low 5-year survival (79.9\%). Survival for SLE patients in North America showed marvelous improvement in the second half of the century. From 1975 to 1990, the 10-year survival improved obviously from 64 to $87 \%$. Even more improvement has taken place from 1990 to 2004, when the 20year survival increased to $78 \%$ [10].

Nevertheless, as shown by Jorge et al. [12], this fabulous decrease in mortality seems to have plateaued after the 2000s. In contrast to the general population, early mortality remains substantially higher in SLE patients. The causes of this increased mortality have been investigated in numerous studies, which suggest that patients with SLE lose 2 decades of life on average [13]. Numerous causes of multiple organ damage are of greatest importance; however, increased activity of SLE disease is also considered an important related factor [14, 15]. Several studies have shown a double peak in early lupus patients with higher mortality rates due to infection or active disease and later in the course of the disease (due to cardiovascular, cerebrovascular, infections, and disease flares). Increased mortality can also be attributed to the disease itself, disease complications, treatment complications, or even unrelated events [16-18].

It is important to note that despite the increase in survival of SLE patients, they continue to experience considerable morbidity and mortality.

\section{Methods}

\section{Aim, study design and patients}

This study aimed to investigate the causes of mortality in SLE patients and the relation between clinical activity, disease-associated end-organ damage, laboratory markers and mortality.

In this retrospective study, the medical records of all SLE patients under follow-up at the outpatient and inpatient clinics of Cairo and Kafr Elsheikh University hospitals through the period from November 2014 to August 2019 were included. Adult patients were included if they fulfilled the 2012 criteria of Systemic Lupus International Collaborating Clinics (SLICC) [19].

\section{Data collection}

The following data were retrieved from the records of eligible patients: demographics characteristics: age and duration of disease, comorbidities, complete blood count, immunological profile, SLE Disease Activity Index (SLEDAI) [20], SLICC Damage Index score [21], drug therapy, and cause of mortality in deceased persons.

\section{Statistical analysis}

Continuous data were expressed as mean \pm SD. An independent-sample $t$ test was used for comparing the variables between the two studied groups with group I representing the deceased patients and group II the survived ones. Non-normally distributed data were analyzed using the Mann-Whitney $U$ test. Categorical data were stated as numbers or percentages. Either the chi-square test or the Fisher's exact test was used to analyze the relation between categorical variables. The risk factors for all-cause mortality in patients with SLE were determined using univariate analysis Cox proportional hazard model. Multivariate Cox regression analysis was done for the variables with statistical significance from the univariate analysis. The stepwise method was used for the multivariate analysis, and the results were expressed as 95\% confidential intervals $(95 \% \mathrm{CI})$. Two-tailed tests were used, and $p<0.05$ was considered statistically significant. Data were analyzed using SPSS 13.0 (SPSS Inc., Chicago, IL, USA).

\section{Results}

We retrieved the medical records of 771 SLE patients during the study period; of them, 34 patients $(4.4 \%)$ deceased. Each group's demographic data is illustrated in Table 2. Infectious causes (35.29\%), cardiopulmonary causes $(26.48 \%)$, renal causes (14.7\%), neuropsychiatric causes $(5.88 \%)$, gastrointestinal causes (2.94\%), and, ultimately, unexplained causes $(14.7 \%)$ were causes of death (Table 1).

Regarding the demographic data, the sex, age and disease duration did not differ in both groups. Subjects who died had lower complement 3 (C3) level, more anemia, lymphopenia, neutropenia, leukocytosis, thrombocytopenia, and decreased glomerular filtration rate $($ GFR $<50 \%)$. Subjects who died had a significantly higher incidence of infection, end-stage renal disease (ESRD), and cardiopulmonary complications. There were also significant differences between the two groups in glucocorticoid dosage with more immunosuppressants (mofetil and cyclophosphamide) treatment observed in patients who died. SLEDAI and SLICC damage index were both significantly higher in deceased persons reflecting higher disease activity and end-organ damage (Tables 2, 3 and 4) 
Table 1 Distribution of the studied cases according to cause of death $(n=34)$

\begin{tabular}{ll}
\hline Cause of death & No. (\%) \\
\hline Renal failure & $2(5.8 \%)$ \\
Acute leukemia and sepsis & $1(2.9 \%)$ \\
Acute pulmonary embolism & $1(2.9 \%)$ \\
Alveolar hemorrhage & $2(5.9 \%)$ \\
Aspiration pneumonia: septic shock & $1(2.9 \%)$ \\
BM depression: septic shock & $2(5.8 \%)$ \\
Brainstem vasculitis: acute hydrocephalus & $1(2.9 \%)$ \\
Cardiac arrest of uncertain cause & $2(5.88 \%)$ \\
CNS lupus, died following plasmapheresis & $1(2.9 \%)$ \\
Infected ventriculoperitoneal shunt & $1(2.9 \%)$ \\
Peptic ulcer: massive hematemesis & $1(2.9 \%)$ \\
Pulmonary embolism with superadded severe infection & $1(2.9 \%)$ \\
Renal failure, heart failure & $1(2.9 \%)$ \\
Renal lupus & $1(2.9 \%)$ \\
Respiratory failure & $1(2.9 \%)$ \\
Sepsis & $8(23.5 \%)$ \\
Severe pulmonary HTN: Rt-sided HF & $1(2.9 \%)$ \\
Suicide during active CNS lupus & $1(2.9 \%)$ \\
Unknown causes & $5(14.7 \%)$ \\
\hline BM Bons marow, &
\end{tabular}

BM Bone marrow, CNS Central nervous system, DIC Disseminated intravascular coagulopathy, HTH Hypertension, HF Heart failure

Univariate cox regression model stated that lymphopenia $(p<0.001)$, thrombocytopenia $(p<0.001)$, low C3 levels $(p<0.007)$, lower GFR $(p=0.003)$, ESRD $(p<$ $0.001)$, SLICC damage index $(p=0.001)$, immunosuppressant drugs and methylprednisone pulse therapy, high steroid daily use $(p=0.001)$, and infections $(p<0.001)$ are risk factors for mortality. While in the multivariate analysis, lymphopenia $(p=0.017)$, lower GFR $(p=$ $0.002), \operatorname{ESRD}(p=0.001)$, and high steroid daily dose ( $p$ $=0.016)$ were independent risk factors for mortality (Table 5).

\section{Discussion}

In this study of Egyptian SLE cohort, we reported mortality rate of $4.4 \%$ (with infection and cardiopulmonary issues as the leading causes of death). Of course, if this is compared to the mortality rate of the Egyptian population which ranged between 5.8 and 6 per 1000 people in the same duration of our study, the lupus burden will be very obvious. Overall, our cohort mortality is comparable to the findings of many researches from other countries [22-28], and while the leading cause of death is not compatible with that of many Western and American nations
[16, 17, 22, 23], which stated cardiopulmonary causes as the leading cause of death, it goes in accordance with many studies with a recent one published in 2018 that stated infection as the leading cause of death. Of course, race and more aggressive treatment are contributing factors [24-28].

A wide range of demographic, clinical, and laboratory variables have been postulated as risk factors for infections in SLE. These include low socioeconomic status, nephritis, high disease activity, low complement level, and the degree of immunosuppression therapy [28-31].

Generally, cardiovascular disease, infection, and active disease are the main specific causes of death in SLE populations. Typically, in the first few years of illness, the primary causes of death are serious infection due to immunosuppression or death from complications of active disease such as lupus nephritis or neuropsychiatric lupus, whereas long-term damage such as ESRD, treatment complications, and, most importantly, cardiovascular disease are primary causes of late death [32-34].

Of utmost importance is the cardiovascular risk in SLE specially accelerated atherosclerosis. Premature atherosclerosis is an apparent leading cause of SLE morbidity and mortality. The likelihood of death due to cardiovascular disease remains largely unchanged despite the decrease in all-cause mortality in SLE over the past 20 years $[3,35,36]$.

There was no statistical difference regarding the demographic data among died and survived groups. This is not in accordance with many studies which reported sex and disease duration as risk factor for mortality, but the most consistent finding in these studies was that the overall standardized mortality rate in men was comparable to that in women. Although many studies reported a difference in demographic data, they were always in controversy that may be explained by different environmental factors, ethnic group, and even accessibility of medical care [7, 29-31, 33-38]. Nevertheless, 21 deceased patients were of less than 33 years with disease duration of less than 5 years which represent a high early mortality in relation to remaining 13 patients.

When we tried to figure out the specific-cause mortality, we noticed that patients with some important organ involvement had significantly higher mortality as end-stage renal failure and cardiopulmonary complications. Also, patients who died had lower C3 level, more anemia, lymphopenia, neutropenia, leukocytosis, thrombocytopenia, and lower glomerular filtration rate $<50 \%$. There was also a statistical significant difference between the two groups in glucocorticoid and immunosuppressant (mofetil and 
Table 2 Relation between mortality and demographic, laboratory and immunological parameters

\begin{tabular}{|c|c|c|c|}
\hline & \multicolumn{2}{|l|}{ Mortality } & \multirow[t]{2}{*}{$P$} \\
\hline & Survived $(n=737)$ & Died $(n=34)$ & \\
\hline \multicolumn{4}{|l|}{ Personal history } \\
\hline \multicolumn{4}{|l|}{ Sex } \\
\hline Male & $59(8 \%)$ & $4(11.8 \%)$ & \multirow[t]{2}{*}{$\mathrm{FE}_{p}=0.351$} \\
\hline Female & 678 (92\%) & 30 (88.2\%) & \\
\hline \multicolumn{4}{|l|}{ Age (years) } \\
\hline Mean \pm SD. & $28.2 \pm 8.7$ & $28.4 \pm 11.3$ & \multirow[t]{2}{*}{0.576} \\
\hline Median (min.-max.) & $27(12-60)$ & $27(12-67)$ & \\
\hline \multicolumn{4}{|l|}{ Age of onset } \\
\hline Mean \pm SD. & $22.1 \pm 8.6$ & $23.1 \pm 9.4$ & \multirow[t]{2}{*}{0.647} \\
\hline Median (min.-max.) & $20(2-52)$ & $20(10-49)$ & \\
\hline \multicolumn{4}{|l|}{ Duration (years) } \\
\hline Mean \pm SD. & $6.1 \pm 4.7$ & $5.7 \pm 5.4$ & \multirow[t]{2}{*}{0.223} \\
\hline Median (min.-max.) & $5(0.2-34)$ & $4(0.3-22)$ & \\
\hline \multicolumn{4}{|l|}{ Lab } \\
\hline Anemia & $584(79.2 \%)$ & 33 (97.1\%) & $0.011^{*}$ \\
\hline Autoimmune & $136(18.5 \%)$ & $9(26.5 \%)$ & 0.242 \\
\hline \multicolumn{4}{|l|}{ Leucopenia } \\
\hline Mean \pm SD. & $0.6 \pm 0.8$ & $0.7 \pm 0.8$ & \multirow[t]{2}{*}{0.264} \\
\hline Median (min.-max.) & $0(0-3.9)$ & $1(0-3)$ & \\
\hline Lymphopenia & 287 (38.9\%) & $26(76.5 \%)$ & $<0.001^{*}$ \\
\hline Neutropenia & $67(9.1 \%)$ & $8(23.5 \%)$ & ${ }^{\mathrm{FE}} p=0.012^{*}$ \\
\hline Leucocytosis & $156(21.2 \%)$ & $17(50 \%)$ & $<0.001^{*}$ \\
\hline Thrombocytopenia & $151(20.5 \%)$ & $18(52.9 \%)$ & $<0.001^{*}$ \\
\hline Thrombocytosis & $102(13.8 \%)$ & $9(26.5 \%)$ & $\mathrm{FE}_{p}=0.075$ \\
\hline \multicolumn{4}{|l|}{ Autoimmune profile } \\
\hline ANA & $696(94.4 \%)$ & 31 (91.2\%) & $\mathrm{FE}_{p}=0.435$ \\
\hline Anti-DNA & $483(65.5 \%)$ & 19 (55.9\%) & 0.248 \\
\hline Decreased C3 & $434(58.9 \%)$ & $29(85.3 \%)$ & $0.002^{*}$ \\
\hline Decreased C4 & $359(48.7 \%)$ & $22(64.7 \%)$ & 0.068 \\
\hline Anti Smith & $50(6.8 \%)$ & $2(5.9 \%)$ & $\mathrm{FE}_{p}=1.000$ \\
\hline
\end{tabular}

Anti-dsDNA Anti-double stranded DNA antibodies, ANA Antinuclear antibody, C3 Complement 3, C4 Complement 4, $\chi^{2}$ Chi-square test, FE Fisher exact, U MannWhitney test, $P p$ value for association between different categories

*Statistically significant at $p \leq 0.05$

cyclophosphamide) therapy. The link between mortality and the intake of corticosteroids and immunosuppressants could not be discussed without knowing the accurate doses and treatment duration of these drugs. SLEDAI and SLICC damage index were both significantly higher in deceased persons reflecting higher disease activity and end-organ damage. Most of these items reflect high disease activity and cumulative damage, and this emphasizes the utmost importance of disease control and standardized drug therapy.

Similarly, the prevalence of the various causes of death in SLE was investigated in a meta-analysis by Yurkovitch et al. [37]. Twelve trials, including 27,123 SLE patients with 4993 deaths, were chosen. The highest mortality rate was observed for SLE patients with renal disease, and the risk of death due to infection, renal disease, and cardiovascular disease was significantly increased overall. 
Table 3 Relation between mortality and different clinical parameters

\begin{tabular}{|c|c|c|c|}
\hline & \multicolumn{2}{|l|}{ Mortality } & \multirow[t]{2}{*}{$P$} \\
\hline & Survived $(n=737)$ & Died $(n=34)$ & \\
\hline \multicolumn{4}{|l|}{ CVA } \\
\hline Absent & $713(96.7 \%)$ & $32(94.1 \%)$ & \multirow[t]{2}{*}{${ }^{M C} C_{p}=0.180$} \\
\hline Present & $24(3.2 \%)$ & $2(5.8 \%)$ & \\
\hline Neuropathy & $49(6.6 \%)$ & $4(11.8 \%)$ & $\mathrm{FE}_{p}=0.284$ \\
\hline Transverse myelitis & $2(0.3 \%)$ & $0(0 \%)$ & ${ }^{\mathrm{FE}} p=1.000$ \\
\hline GFR & $10(1.4 \%)$ & $4(11.8 \%)$ & $\mathrm{FE}_{p}=0.002^{*}$ \\
\hline \multicolumn{4}{|l|}{ ESRD } \\
\hline Absent & 724 (98.2\%) & $24(70.6 \%)$ & \multirow[t]{2}{*}{${ }^{\mathrm{FE}} p<0.001^{*}$} \\
\hline Present & $13(1.8 \%)$ & $10(29.4 \%)$ & \\
\hline Pulmonary hypertension & $32(4.3 \%)$ & $3(8.8 \%)$ & $\mathrm{FE}_{p}=0.196$ \\
\hline Pulmonary fibrosis & $27(3.7 \%)$ & $2(5.9 \%)$ & $\mathrm{FE}_{p}=0.370$ \\
\hline Pulmonary fibrosis & $10(1.4 \%)$ & $2(5.9 \%)$ & $\mathrm{FE} p=0.094$ \\
\hline Pulmonary infarction & $5(0.7 \%)$ & $2(5.9 \%)$ & $\mathrm{FE}_{p}=0.035^{*}$ \\
\hline Shrink lung & $14(1.9 \%)$ & $3(8.8 \%)$ & ${ }^{\mathrm{FE}} p=0.035^{*}$ \\
\hline Angina & $15(2 \%)$ & $0(0 \%)$ & $\mathrm{FE}_{p}=1.000$ \\
\hline Myocardial infarction & $2(0.3 \%)$ & $0(0 \%)$ & $\mathrm{FE}_{p}=1.000$ \\
\hline Cardio-myopathy & $35(4.7 \%)$ & $7(20.6 \%)$ & ${ }^{\mathrm{FE}} p=0.002^{*}$ \\
\hline Valvular & $80(10.9 \%)$ & $6(17.6 \%)$ & ${ }^{\mathrm{FE}} p=0.257$ \\
\hline Pericarditis & $71(9.6 \%)$ & $2(5.9 \%)$ & $\mathrm{FE} p=0.763$ \\
\hline Venous thrombosis & $82(11.1 \%)$ & $4(11.8 \%)$ & ${ }^{\mathrm{FE}} p=0.785$ \\
\hline Bowel infarction & $31(4.2 \%)$ & $1(2.9 \%)$ & $\mathrm{FE} p=1.000$ \\
\hline \multicolumn{4}{|l|}{ AVN } \\
\hline No & $686(93.1 \%)$ & $30(88.2 \%)$ & \multirow[t]{3}{*}{${ }^{M C} C_{p}=0.053$} \\
\hline Unilateral & $26(3.5 \%)$ & $0(0 \%)$ & \\
\hline Bilateral & $25(3.4 \%)$ & $4(11.8 \%)$ & \\
\hline OP with fracture & $36(4.9 \%)$ & $5(14.7 \%)$ & ${ }^{\mathrm{FE}} p=0.029^{*}$ \\
\hline Osteomyelitis & $0(0 \%)$ & $0(0 \%)$ & - \\
\hline Premature gonadal Failure & $3(0.4 \%)$ & $0(0 \%)$ & $\mathrm{FE}_{p}=1.000$ \\
\hline Diabetes & $55(7.5 \%)$ & $4(11.8 \%)$ & $\mathrm{FE}_{p}=0.321$ \\
\hline Malignancy & $0(0 \%)$ & $1(2.9 \%)$ & ${ }^{\mathrm{FE}} p=0.044^{*}$ \\
\hline Infection & $311(42.2 \%)$ & $27(79.4 \%)$ & $<0.001^{*}$ \\
\hline \multicolumn{4}{|l|}{ SLEDAI } \\
\hline Mean \pm SD. & $8.8 \pm 8.3$ & $9.8 \pm 6.3$ & \multirow[t]{2}{*}{$0.024^{*}$} \\
\hline Median (min.-max.) & $6(0-43)$ & $8(0-26)$ & \\
\hline $\mathrm{APL}+\mathrm{ve}$ & $208(28.2 \%)$ & $9(26.5 \%)$ & 0.824 \\
\hline \multicolumn{4}{|l|}{ SLICC calculated } \\
\hline Mean \pm SD & $1.5 \pm 1.6$ & $3.1 \pm 2.6$ & \multirow[t]{2}{*}{$<0.001^{*}$} \\
\hline Median (min.-max.) & $1(0-8)$ & $3(0-11)$ & \\
\hline
\end{tabular}

ESRD End-stage renal disease, CVA Cerebrovascular accident, GFR Glomerular filtration rate, AVN Avascular necrosis, OP Osteoporosis, APL Antiphospholipid antibodies, SLICC Systemic Lupus International Collaborating Clinics Damage Index score, SLEDAI SLE Disease Activity Index, $X^{2}$ Chi-square test, FE Fisher exact, MC Monte Carlo, $p P$ value for association between different categories

*Statistically significant at $p \leq 0.05$ 
Table 4 Relation between mortality and drug therapy

\begin{tabular}{|c|c|c|c|}
\hline & \multicolumn{2}{|l|}{ Mortality } & \multirow[t]{2}{*}{$P$} \\
\hline & Survived $(n=737)$ & Died $(n=34)$ & \\
\hline \multicolumn{4}{|l|}{ Drugs } \\
\hline Cyclophosphamide & $280(38 \%)$ & $24(70.6 \%)$ & $0.001^{*}$ \\
\hline Azathioprine & $546(74.1 \%)$ & $21(61.8 \%)$ & 0.111 \\
\hline Mofetil & 71 (9.6\%) & $10(29.4 \%)$ & $\mathrm{FE}_{p}=0.002^{*}$ \\
\hline Methylprednisolone & $454(61.6 \%)$ & $29(85.3 \%)$ & $0.005^{*}$ \\
\hline \multicolumn{4}{|l|}{ Corticosteroids } \\
\hline 15 & $151(20.5 \%)$ & $1(2.9 \%)$ & \multirow[t]{3}{*}{$<0.001^{*}$} \\
\hline $15-35$ & $381(51.7 \%)$ & $9(26.5 \%)$ & \\
\hline$>40$ & $205(27.8 \%)$ & $24(70.6 \%)$ & \\
\hline Anti-malarial & $633(85.9 \%)$ & 27 (79.4\%) & $\mathrm{FE}_{p}=0.314$ \\
\hline
\end{tabular}

$x^{2}$ Chi-square test, FE Fisher exact, $U$ Mann-Whitney test, $p P$ value for association between different categories

${ }^{*}$ Statistically significant at $p \leq 0.05$

We confirmed that lupus-related organ involvements had the strongest impact on the prognosis of SLE patients by the univariate and multivariate hazard regression analysis. Lymphopenia, low GFR, ESRD, and high steroid daily were the strongest independent risks of mortality by multivariate hazard regression analysis. This reflects the effect of cumulative renal disease (GFR and ESRD), risk of infection (lymphopenia), and higher disease activity (high steroid daily dose). This was similar to the reports from western countries including the UK, France, and Finland [16, 17, 22]. Several other studies from developing countries such as Thailand, Malaysia, and Brazil described similar results where the renal burden of the disease was very obvious. Unfortunately, data from eastern African countries is not available [3,24-28]. Our findings are not in accordance with a Chinese study which found that renal affection was not identified as a risk factor for mortality by the hazard analyses [28].

Lymphopenia is a common finding in active SLE patients that was reported in $90 \%$ of lupus patients throughout the disease course. Other factors may cause lymphopenia including infections and medications such as corticosteroids and cytotoxic agents. Lymphopenia has been reported as a risk factor for opportunistic and serious infections [39-41]. Although not reported in many studies as a risk factor for mortality [22-28], it was raised up in our study, giving great importance for hematological changes in SLE patients.

This research has some limitations. Despite considerable efforts to determine the cause of death in each subject, in 5 patients who were reported as an unknown cause of death, we were unable to confirm this, and more than one cause was also apparent in a few cases.
Unfortunately, accurate doses and treatment duration of the immunosuppressants intake were not available in this retrospective study. Definitely, the small number of cases is a limitation of the study so a multicenter, prospective longitudinal study with larger subject number will more accurately quantify mortality and evaluate the impact of treatment on mortality in Egyptian SLE patients.

\section{Conclusion}

Infections and cardiopulmonary complications are the leading causes of death in two centers caring for Egyptian SLE patients. Lymphopenia, end-stage renal failure, and high steroid daily use were associated with poor outcomes.

Tight strict control of the disease activity should be targeted and regular assessment of the response to immunosuppressant with strict adherence to the management recommendations is mandatory for SLE patients. With the advent of earlier diagnosis and recognition of disease, as well as the introduction of newer less toxic therapeutic measures, it would be expected that mortality in SLE patients would decline but increased mortality in comparison to general populations remains part of the natural history of lupus.

Future research, with particular emphasis on infection risk factors, cardiopulmonary diseases and lupus nephritis, should concentrate on the development of novel therapies and the treatment of comorbid conditions of SLE. As always, screening and prevention are the keys to preventing illness and therapy complications.

The importance of this research lies in being one of the earliest studies addressing mortality problems in African SLE patients, which may stimulate further reports 


\begin{tabular}{|c|c|c|c|c|}
\hline \multirow{2}{*}{ Mortality } & \multicolumn{2}{|r|}{ Univariate } & \multicolumn{2}{|r|}{ Multivariate } \\
\hline & $\mathbf{p}$ & HR (95\% C.I) & $\mathbf{p}$ & HR (95\%C.I) \\
\hline Age (years) & 0.129 & $0.967(0.925-1.010)$ & & \\
\hline Age of onset & 0.085 & $1.031(0.996-1.067)$ & & \\
\hline Lymphopenia & $<0.001^{*}$ & $5.303^{*}(2.399-11.721)$ & $0.017^{*}$ & $3.185^{*}(1.229-8.250)$ \\
\hline Thrombocytopenia & $<0.001^{*}$ & $3.936^{*}(2.005-7.729)$ & 0.198 & $1.706(0.757-3.845)$ \\
\hline Anti-DNA & 0.328 & $0.712(0.361-1.405)$ & & \\
\hline Decreased C3 & $0.007^{*}$ & $3.712^{*}(1.436-9.594)$ & 0.675 & $1.250(0.441-3.545)$ \\
\hline Anti Smith & 0.511 & $0.613(0.142-2.639)$ & & \\
\hline GFR $<50 \%$ & $0.003^{*}$ & $5.064^{*}(1.725-14.869)$ & $0.002^{*}$ & $6.660^{*}(2.001-22.163)$ \\
\hline ESRD & $<0.001^{*}$ & $11.743^{*}(5.559-24.806)$ & $0.001^{*}$ & $7.861^{*}(2.423-25.498)$ \\
\hline Pulmonary Fibrosis & 0.274 & $2.346(0.509-10.809)$ & & \\
\hline Venous Thrombosis & 0.663 & $1.262(0.443-3.594)$ & & \\
\hline Diabetes & 0.949 & $0.966(0.333-2.805)$ & & \\
\hline SLICC calculated & $<0.001^{*}$ & $1.311^{*}(1.138-1.510)$ & 0.259 & $0.875(0.695-1.103)$ \\
\hline \multicolumn{5}{|l|}{ Drugs } \\
\hline Cyclophosphamide & $0.023^{*}$ & $1.102^{*}(1.013-1.199)$ & 0.640 & $0.976(0.880-1.082)$ \\
\hline Mofetil & $<0.001^{*}$ & $3.757^{*}(1.793-7.874)$ & 0.775 & $0.874(0.348-2.196)$ \\
\hline Methylprednisolone & $0.003^{*}$ & $4.176^{*}(1.613-10.808)$ & 0.392 & $1.662(0.519-5.319)$ \\
\hline Corticosteroids $(>40)$ & $<0.001^{*}$ & $6.425^{*}(3.070-13.446)$ & $0.016^{*}$ & $2.874^{*}(1.218-6.781)$ \\
\hline Infection & $<0.001^{*}$ & $4.603^{*}(2.002-10.585)$ & 0.211 & $1.874(0.700-5.020)$ \\
\hline SLEDAI & 0.628 & $1.009(0.972-1.049)$ & & \\
\hline APL & 0.904 & $0.954(0.445-2.047)$ & & \\
\hline
\end{tabular}

ESRD End-stage renal disease, GFR Glomerular filtration rate, APL Antiphospholipid antibodies, SLICC Systemic Lupus International Collaborating Clinics Damage Index score, SLEDAI SLE Disease Activity Index, Anti-dsDNA Anti-double-stranded DNA antibodies, C3 Complement 3, HR Hazard ratio, CI Confidence interval All variables with $p<0.05$ was included in the multivariate

*Statistically significant at $p \leq 0.05$

for further comparison with Asian, American, and Western countries' reports.

\section{Abbreviations}

ESRD: End-stage renal disease; GFR: Glomerular filtration rate; LN: Lupus nephritis; SLE: Systemic lupus erythematosus; SLEDAI: SLE Disease Activity Index; SLICC: Systemic Lupus International Collaborating Clinics

Acknowledgements

None

Authors' contributions

All authors have contributed to designing the study, collecting and analyzing, interpretation of the data, and preparing and revising the manuscript. AM and Al did the design of the study, recruitment of patients, data collection, randomizing, assessment, statistical analysis and data interpretation, manuscript preparation, and manuscript revision The authors have read and approved the final version of the manuscript.
Funding

This study has no funding sources.

Availability of data and materials

Available

Ethics approval and consent to participate

We confirm none of the present study's procedures had violated the principles stated by the latest version of the Declaration of Helsinki. The protocol of the present study was registered by the local ethics committee of Kafr Elsheikh Faculty of Medicine with approval code MKSU4-11-2020. We confirm that the manuscript has been read and approved by all the authors, that the requirements for authorship as stated earlier in this document have been met, and that each author believes that the manuscript represents honest work.

Consent for publication Not applicable. 


\section{Competing interests}

The authors declare no competing interests.

\section{Author details}

${ }^{1}$ Faculty of Medicine, Cairo University, Cairo, Egypt. ${ }^{2}$ Faculty of Medicine, Kafr El Sheikh University, Kafr El Sheikh, Egypt.

Received: 26 December 2020 Accepted: 29 January 2021

Published online: 22 February 2021

\section{References}

1. Mortada MA, Zidan HE, Abdelsalam NA et al (2020) Gene XRCC1Arg399GIn polymorphism and its genotype variations: clinical associations in Egyptian systemic lupus erythematosus patients. Egypt Rheumatol Rehabil 47:2

2. Elessawi DF, Mahmoud GA, ElSawy WS, Shieba HF, Goda SM (2019) Antinucleosome antibodies in systemic lupus erythematosus patients: relation to disease activity and lupus nephritis. Egypt Rheumatol 41(1): $31-34$

3. Fors Nieves CE, Izmirly PM (2016) Mortality in systemic lupus erythematosus: an updated review. Curr Rheumatol 18(4):21

4. Bernatsky S, Boivin JF, Joseph L, Manzi S, Ginzler E, Gladman DD et al (2006) Mortality in systemic lupus erythematosus. Arthritis Rheum 54(8): 2550-2557

5. Kasitanon N, Magder LS, Petri M (2006) Predictors of survival in systemic lupus erythematosus. Medicine (Baltimore) 85(3):147-156

6. Doria A, laccarino L, Ghirardello A, Zampieri S, Arienti S, SarziPuttini P et al (2006) Long-term prognosis and causes of death in systemic lupus erythematosus. Am J Med 119(8):700-706

7. Andrade RM, Alarcon GS, Fernandez M, Apte M, Vila LM, Reveille JD et al (2007) Accelerated damage accrual among men with systemic lupus erythematosus: XLIV. Results from a multiethnic U.S. cohort. Arthritis Rheum 56(2):622-630

8. Bujan S, Ordi-Ros J, Paredes J, Mauri M, Matas L, Cortes J et al (2003) Contribution of the initial features of systemic lupus erythematosus to the clinical evolution and survival of a cohort of Mediterranean patients. Ann Rheum Dis 62(9):859-865

9. Hersh AO, Trupin L, Yazdany J, Panopalis P, Julian L, Katz P et al (2010) Childhood-onset disease as a predictor of mortality in an adult cohort of patients with systemic lupus erythematosus. Arthritis Care Res (Hoboken) 62(8):1152-1159

10. Urowitz MB, Gladman DD, Tom BD, Ibanez D, Farewell VT (2008) Changing patterns in mortality and disease outcomes for patients with systemic lupus erythematosus. J Rheumatol 35(11):2152-2158

11. Flower C, Hennis AJ, Hambleton IR, Nicholson GD, Liang MH, Barbados National Lupus Registry, G (2012) Systemic lupus erythematosus in an African Caribbean population: incidence, clinical manifestations, and survival in the Barbados National Lupus Registry. Arthritis Care Res (Hoboken) 64(8): 1151-1158

12. Jorge AM, Lu N, Zhang Y, Rai SK, Choi HK (2018) Unchanging premature mortality trends in systemic lupus erythematosus: a general populationbased study (1994-2014). Rheumatology 57(2):337-344

13. Gordon C, Amissah-Arthur M-B, Gayed M et al (2018) The British Society of Rheumatology guidelines for the management of systemic lupus erythematosus in adults. Rheumatology 57(1):14-18

14. Chambers SA, Allen E, Rahman A, Isenberg D (2009) Damage and mortality in a group of British patients with systemic lupus erythematosus followed up for over 10 years. Rheumatology 48(6):673-675

15. Urowitz MB, Gladmann DD (1999) Evolving spectrum of mortality and morbidity in SLE (editorial). Lupus 8:253-255

16. Yee CS, Su L, Toescu V, Hickman R, Situnayake D, Bowman S, Farewell V, Gordon C (2015) Birmingham SLE cohort: outcomes of a large inception cohort followed up for 21 years. Rheumatology 54(5):836-843

17. Rees F, Doherty M, Grainge MJ, Lanyon P, Davenport G, Zhang W (2016) Mortality in systemic lupus erythematosus in the United Kingdom 19992012. Rheumatology 55(5):854-860

18. Anver H, Dubey S, Fox J (2019) Changing trends in mortality in systemic lupus erythematosus? An analysis of SLE inpatient mortality at University Hospital Coventry and Warwickshire NHS Trust from 2007 to 2016. Rheumatol Int 39:2069-2075
19. Petri M, Orbai AM, Alarcõn GS, Gordon C, Merrill JT, Fortin PR et al (2012) Derivation and validation of the systemic lupus international collaborating clinics classification criteria for systemic lupus erythematosus. Arthritis Rheum 64(8):2677-2686

20. Hawker G, Gabriel S, Bombardier C, Goldsmith C, Caron D, Gladman D (1993) A reliability study of SLEDAl: a disease activity index for systemic lupus erythematosus. J Rheumatol 20:657-660

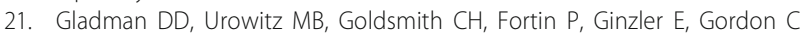
et al (1997) The reliability of the Systemic Lupus International Collaborating Clinics/American College of Rheumatology Damage Index in patients with systemic lupus erythematosus. Arthritis Rheum 40(5): 809-813

22. Thomas G, Mancini J, Jourde-Chiche N et al (2014) Mortality associated with systemic lupus erythematosus in France assessed by multiple-cause-ofdeath analysis. Arthritis Rheum 66:2503-2511

23. Elfving P, Puolakka K, Kautiainen $\mathrm{H}$ et al (2014) Mortality and causes of death among incident cases of systemic lupus erythematosus in Finland 2000-2008. Lupus 23:1430-1434

24. Kasitanon N, Louthrenoo W, Sukitawut W et al (2002) Causes of death and prognostic factors in Thai patients with systemic lupus erythematosus. Asian Pac J Allergy Immunol 20:85-91

25. Yeap SS, Chow SK, Manivasagar M et al (2001) Mortality patterns in Malaysian systemic lupus erythematosus patients. Med J Malaysia 56:308-312

26. Hendler JV, De SL, Dc DFZ et al (2017) Survival analysis of patients with systemic lupus erythematosus in a tertiary hospital in southern Brazil. Clin Rheumatol 36(9):2005-2010

27. Dzifa D, Boima V, Yorke E et al (2018) Predictors and outcome of systemic lupus erythematosus (SLE) admission rates in a large teaching hospital in sub-Saharan Africa. Lupus 27(2):336-342

28. Mu L, Hao Y, Fan Y, Huang H, Yang X, Xie A, Zhang X, Ji L, Geng Y, Zhang Z (2018) Mortality and prognostic factors in Chinese patients with systemic lupus erythematosus. Lupus 27(10):1742-1752

29. Hiraki LT, Feldman CH, Marty FM et al (2017) Serious infection rates among children with systemic lupus erythematosus enrolled in Medicaid. Arthritis Care Res 69(11):1620-1626

30. Feldman CH, Hiraki LT, Winkelmayer WC et al (2015) Serious infections among adult Medicaid beneficiaries with systemic lupus erythematosus and lupus nephritis. Arthritis Rheumatol 67(6):1577-1585

31. Rúa-Figueroa I, López-Longo J, Galindoizquierdo M et al (2017) Incidence, associated factors and clinical impact of severe infections in a large, multicentric cohort of patients with systemic lupus erythematosus. Semin Arthritis Rheum 47(1):38-45

32. Moss KE, Ioannou Y, Sultan SM, Haq I, Isenberg DA (2002) Outcome of a cohort of 300 patients with systemic lupus erythematosus attending a dedicated clinic for over two decades. Ann Rheum Dis 61(5):409-413

33. Bjornadal L, Yin L, Granath F, Klareskog L, Ekbom A (2004) Cardiovascular disease a hazard despite improved prognosis in patients with systemic lupus erythematosus: results from a Swedish population based study 196495. J Rheumatol 31(4):713-719

34. Cartella S, Cavazzana I, Ceribelli A, Inverardi F, Tincani A, Franceschini F (2013) Evaluation of mortality, disease activity, treatment, clinical and immunological features of adult and late onset systemic Lupus erythematosus. Autoimmunity 46(6):363-368

35. Agarwal S, Elliott JR, Manzi S (2009) Atherosclerosis risk factors in systemic lupus erythematosus. Curr Rheumatol Rep 11(4):241-247

36. Packard RR, Libby $P$ (2008) Inflammation in atherosclerosis: from vascular biology to biomarker discovery and risk prediction. Clin Chem 54(1):24-38

37. Yurkovich M, Vostretsova K, Chen W, Avina-Zubieta JA (2014) Overall and cause-specific mortality in patients with systemic lupus erythematosus: a meta-analysis of observational studies. Arthritis Care Res (Hoboken) 66(4): 608-616

38. Sobhy N, Niazy MH, Kamal A (2020) Lymphopenia in systemic lupus erythematosus patients: is it more than a laboratory finding? Egypt Rheumatol 42(1):23-26

39. Merayo-Chalico J, Gómez-Martín D, Piñeirúa-Menéndez A, Santana-De Anda K, Alcocer-Varela J (2013) Lymphopenia as risk factor for development of severe infections in patients with systemic lupus erythematosus: a casecontrol study. QJM 106(5):451-457 
40. Yu HH, Wang LC, Lee JH, Lee CC, Yang YH, Chiang BL (2007) Lymphopenia is associated with neuropsychiatric manifestations and disease activity in pediatric systemic lupus erythematosus patients. Rheumatology (Oxford) 46(9):1492-1494

41. Faddah S, Elwakd M, Aboelenein A, Hussein M (2014) Lymphopenia and systemic lupus erythematosus, a preliminary study: correlation with clinical manifestations, disease activity and damage indices. Egypt Rheumatol 36(3): $125-130$

\section{Publisher's Note}

Springer Nature remains neutral with regard to jurisdictional claims in published maps and institutional affiliations.

Submit your manuscript to a SpringerOpen ${ }^{\circ}$ journal and benefit from:

- Convenient online submission

- Rigorous peer review

- Open access: articles freely available online

High visibility within the field

- Retaining the copyright to your article

Submit your next manuscript at $\boldsymbol{\nabla}$ springeropen.com 